\title{
LA DEMOCRACIA COMO BIEN JURÍDICO TUTELADO DE LOS DELITOS ELECTORALES
}

\section{Osvaldo Ramírez Ortiz ${ }^{1}$}

En el escenario nacional, resulta necesario robustecer la tutela de la libre expresión de la voluntad popular, garantizando la equidad y el equilibrio en las contiendas electorales, al evitar abusos, arbitrariedades, y ventajas ilícitas, toda vez que son crecientes los señalamientos que dan cuenta del despliegue y comisión recurrente de estas conductas, las que en muchas ocasiones son determinantes en la configuración de los resultados de los procesos electorales a todos los niveles, lo que erige en imperioso el estudio de dichos comportamientos.

Por lo anterior, el rubro relativo a los delitos electorales ha cobrado notable preeminencia a últimas fechas, y fue por ello que la normatividad en la materia ha sido susceptible de un reciente proceso de actualización, con la finalidad de responder a los nuevos desafíos.

La actualización legislativa referida se tradujo en una necesidad impostergable, y con ella se pretendió el perfeccionamiento del régimen democrático, del sistema de partidos y de las instituciones electorales de nuestro país, aspiraciones que únicamente podrán tener verificativo mediante la cooperación y la sinergia entre la ciudadanía, la sociedad en su conjunto y el Estado, que unidos permitirán que esa aludida voluntad del pueblo prospere y se respete.

No obstante, el ajuste del tema legislativo, si no encuentra un referente de cumplimiento real, no sirve de mucho, es decir, se debe buscar la manera de garantizar su aplicación; sin embargo, en países como el nuestro, existen factores que ponen en severo riesgo a la democracia.

1 Doctor en Derecho por la Universidad Autónoma de Tlaxcala, ex director de la Facultad de Derecho, Ciencias Políticas y Criminología de esa misma universidad, y líder del Cuerpo Académico en Formación denominado Seguridad Pública, Oralidad y Delincuencia Organizada. Es autor de diversos textos sobre derecho penal, metodología de las ciencias sociales y criminología. 


\section{Contenidos de la reforma electoral de 2014}

A pesar de que el abordaje de la categoría de delitos electorales se remonta al texto constitucional del año de 1814, y disposiciones posteriores hasta llegar a la centenaria Constitución de 1917, se dice que no fue sino hasta la década de los 90's del siglo pasado en la que se le comenzó a conceder la verdadera trascendencia que reviste, ya que fue precisamente en esa época en la que se incorporó de manera debida, en el Código Penal Federal (CPF), otorgándole con ello la verdadera dimensión que implica.

Debemos considerar de modo sustantivo que el parlamentario debió observar su entorno socio-político, donde la influencia de los avances tecnológicos y la presencia de mecanismos de seguimiento digital, nuevos comportamientos anómicos y modus operandi criminales, entre otros aspectos, implicaron nuevos escenarios donde la salvaguarda de la competencia electoral fue uno de los imperativos en la reforma política de 2014.

Así, en el mes de mayo, fue publicada en el Diario Oficial de la Federación, la denominada Ley General en Materia de Delitos Electorales, que reglamenta lo enunciado en el inciso a), fracción XXI, artículo 73, de nuestra Carta Magna. Tal ordenamiento tiene una trascendencia en su matiz regulador de conductas que no se habían prestablecido en el pasado, destacándose la investigación, la persecución y la sanción de conductas típicas que afecten el adecuado desarrollo de los procesos electorales.

La denominada reforma política de febrero de 2014, publicada en el Diario Oficial de la Federación el día 10 de ese mes, mediante decreto que reformó, adicionó y derogó 29 artículos de la Constitución Política de los Estados Unidos Mexicanos en la materia, se puede dividir en cuatro ejes temáticos: Régimen de gobierno; Autoridades electorales; Régimen de partidos, y Creación de nueva legislación.

En el primer eje, relativo al régimen de gobierno, la novedad es la incorporación de la figura de gobierno de coalición, a la que el presidente podrá optar, en cualquier momento de su gestión, después de haber suscrito un convenio con los partidos políticos y obtenido la aprobación respectiva del Senado de la República (art. 89, fracción XVII de la Constitución Política de los Estados Unidos Mexicanos). 
En esta reforma debemos destacar otro cambio importante, como lo es la introducción de la reelección legislativa. Un tema que a lo largo de los años había sido objeto de reserva, y que con esta reforma se decidió abordar, con lo que se puso fin a 8 décadas de no reelección; para efectos de la transformación legislativa en comento, se contempla que los senadores podrán ser electos hasta por dos y los diputados federales hasta por cuatro periodos consecutivos, respectivamente. Sin embargo, los candidatos deberán ser postulados por el mismo partido político, a menos que hayan renunciado a su militancia antes de la mitad de su mandato (artículo 59 de la Constitución Política de los Estados Unidos Mexicanos).

Por cuanto hace a las autoridades electorales, modifica de manera sustancial la estructura y la distribución de la facultad de organización electoral. En primer lugar, la reforma desaparece al Instituto Federal Electoral (IFE), y en su lugar crea al Instituto Nacional Electoral, como ya lo habíamos precisado en líneas preliminares. La función básica del INE será la de organizar las elecciones federales; empero, también se le otorgan facultades en el ámbito local, manteniendo la existencia de los institutos electorales locales, aunque con importantes cambios en sus facultades, integración y nombramiento.

A la par de incrementar el número de consejeros electorales (11), se crea un Servicio Profesional Electoral Nacional, que será regulado por el Instituto Nacional Electoral.

En lo relativo al régimen de partidos, se experimentan algunos cambios de relevancia. Con la reforma, el requisito para mantener el registro se eleva a rango constitucional y ahora se requiere el 3\% de la votación válida emitida en cualquiera de las elecciones que se celebren para la renovación del Poder Ejecutivo o de las Cámaras del Congreso de la Unión.

\section{Legislaciones de reciente creación con motivo de la reforma}

La reforma político electoral aparejó el surgimiento de tres nuevos ordenamientos, a saber: la Ley General de Partidos Políticos, la Ley General 
de Instituciones y Procedimientos Electorales, y la Ley General en Materia de Delitos Electorales.

Los tres nuevos ordenamientos son de carácter general, porque delimitan las facultades de las autoridades federales, estatales y municipales en materia electoral, a diferencia del Código Federal de Instituciones y Procedimientos Electorales (COFIPE), que se refería a casos que tenían que ver únicamente con la competencia de orden federal.

A continuación, realizaremos una breve exposición de las características de estas normativas:

\subsection{Ley General de Partidos Políticos}

La presente Ley es de orden público y de observancia general en el territorio nacional, y tiene por objeto regular las disposiciones constitucionales aplicables a los partidos políticos nacionales y locales, así como distribuir competencias entre la Federación y las entidades federativas en materia de:

a) La constitución de los partidos políticos, así como los plazos y requisitos para su registro legal;

b) Los derechos y obligaciones de sus militantes;

c) Los lineamientos básicos para la integración de sus órganos directivos, la postulación de sus candidatos, la conducción de sus actividades de forma democrática, sus prerrogativas y la transparencia en el uso de recursos;

d) Los contenidos mínimos de sus documentos básicos;

e) Las formas de participación electoral a través de la figura de coaliciones;

f) El sistema de fiscalización de los ingresos y egresos de los recursos;

g) La organización y funcionamiento de sus órganos internos, así como los mecanismos de justicia intrapartidaria;

h) Los procedimientos y sanciones aplicables al incumplimiento de sus obligaciones; 
i) El régimen normativo aplicable en caso de pérdida de registro y liquidación de los partidos políticos, $\mathrm{y}$

j) El régimen jurídico aplicable a las agrupaciones políticas nacionales. $^{2}$

\subsection{Ley General de Instituciones y Procedimientos Electorales}

\section{Artículo 1.}

1. La presente Ley es de orden público y de observancia general en el territorio nacional y para los Ciudadanos que ejerzan su derecho al sufragio en territorio extranjero. Tiene por objeto establecer las disposiciones aplicables en materia de instituciones y procedimientos electorales, distribuir competencias entre la Federación y las entidades federativas en estas materias, así como la relación entre el Instituto Nacional Electoral y los Organismos Públicos Locales.

2. Las disposiciones de la presente Ley son aplicables a las elecciones en el ámbito federal y en el ámbito local respecto de las materias que establece la Constitución.

3. Las Constituciones y leyes locales se ajustaran a lo previsto en la Constitución y en esta Ley.

4. La renovación de los poderes Ejecutivo y Legislativo de la Federación, así como las correspondientes a los poderes Ejecutivo, Legislativo y de los Ayuntamientos en los estados de la Federación, y del Jefe de Gobierno, diputados a la Asamblea Legislativa y los jefes delegacionales del Distrito Federal, se realizarán mediante elecciones libres, auténticas y periódicas, mediante sufragio universal, libre, secreto y directo.

Artículo 2.

1. Esta Ley reglamenta las normas constitucionales relativas a:

a) Los derechos y obligaciones político-electorales de los ciudadanos;

b) La función estatal de organizar las elecciones de los integrantes de los Poderes Legislativo y Ejecutivo de la Unión;

2 Ley General de Partidos Políticos, publicada en el Diario Oficial de la Federación, el 23 de mayo de 2014, Congreso de la Unión, Cámara de Diputados, México, 2014. 
c) Las reglas comunes a los procesos electorales federales y locales, y

d) La integración de los organismos electorales. ${ }^{3}$

Esta ley deberá regular: la celebración de elecciones federales y locales el primer domingo de junio del año que corresponda, en los términos de la Constitución y a partir de 2015, salvo aquellas que se verifiquen en 2018 , las cuales se llevarán a cabo el primer domingo de julio; los mecanismos de coordinación entre los órganos del Ejecutivo Federal en materia de inteligencia financiera y el Instituto Nacional Electoral, que permitan reportar a éste las disposiciones en efectivo que realice cualquier órgano o dependencia de la Federación, de las entidades federativas y de los municipios; los términos en que habrán de realizarse debates de carácter obligatorio entre candidatos; las modalidades y plazos de entrega de los materiales de propaganda; las sanciones aplicables a la promoción de denuncias frívolas; las reglas para garantizar la paridad entre géneros en candidaturas a legisladores federales y locales, las reglas, plazos, instancias y etapas procesales para sancionar violaciones en los procedimientos electorales.

\subsection{Ley General en Materia de Delitos Electorales}

Esta ley dispone que todos los delitos electorales previstos en ordenamientos locales o el federal fueron derogados. La Ley General en Materia de Delitos Electorales es de observancia general en toda la República mexicana.

Este ordenamiento legal establece tipos penales, sanciones y la distribución de competencias, así como las formas de coordinación entre los tres niveles de gobierno, para su investigación y persecución.

En esta ley se incluyó un escenario para anular elecciones y se detallaron conductas ilícitas durante tiempos electorales. ${ }^{4}$

3 Ley General de Instituciones y Procedimientos Electorales, publicada en el Diario Oficial de la Federación, el 23 de mayo de 2014, Congreso de la Unión, Cámara de Diputados, México, 2014. 
Contempla 25 conductas constitutivas de ilícito electoral, tanto en el ámbito local y federal. Entre esas conductas tenemos:

- Obtener o utilizar fondos provenientes de actividades ilícitas para una campaña electoral;

- Obligar o ejercer cualquier tipo de presión sobre los ciudadanos para que voten a favor o en contra de un candidato, partido político, o bien se abstengan de votar;

- Promover, mediante amenaza o promesa de pago o dádiva, el voto en favor o en contra de un determinado partido político o candidato, o bien la abstención de votar.

La reforma establece que a quien tenga calidad de servidor público al momento de incurrir en una conducta ilícita se le impondrán las siguientes sanciones: una sanción de doscientos a cuatrocientos días multa, prisión de tres a nueve años, destitución del cargo, inhabilitación para ocupar cargos públicos y suspensión de los derechos políticos electorales de uno a cinco años. ${ }^{5}$

Esta Ley, tiene como objetivo combatir, sancionar y fortalecer los mecanismos para la prevención de conductas que tengan como propósito alterar la voluntad ciudadana expresada en las urnas, como se advierte en su primer artículo:

"Artículo 1. Esta ley es reglamentaria del artículo 73, fracción XXI, inciso a) de la Constitución Política de los Estados Unidos Mexicanos, en materia de delitos electorales".

Se compone de tres títulos en los que se integran las disposiciones relativas los siguientes rubros:

- Se establecen las disposiciones básicas que se aplican a las leyes generales, tales como: Objeto y definiciones generales, Formas de

${ }^{4}$ Ley General en Materia de Delitos Electorales, publicada en el Diario Oficial de la Federación, el 23 de mayo de 2014, Congreso de la Unión, Cámara de Diputados, México, 2014.

${ }^{5}$ Reforma político electoral, documento publicado por el gobierno federal acerca de esta reforma sustantiva al sistema electoral mexicano, Gobierno de la República, México, 2014, p. 10. 
coordinación entre los tres niveles de gobierno para la investigación, persecución y sanción de los delitos electorales, Los tipos penales en materia electoral, así como reglas comunes para su aplicación, Las competencias, facultades y los mecanismos de coordinación entre la federación y las entidades federativas.

Destaca el analista Omar Granados que "entre los puntos clave de esta ley se determinan nuevas sanciones a ciertos delitos electorales, se reforman las facultades y obligaciones de autoridades, así como la coordinación entre la federación y los estados durante un proceso electoral". ${ }^{6}$

Entre las sanciones aprobadas, se imponen 200 a 400 días de multa y prisión de dos hasta nueve años, a servidores públicos que coaccionen, induzcan o amenacen a sus subordinados para que participen en eventos proselitistas, voten o se abstengan de votar por algún partido o candidato. Si un funcionario condiciona programas gubernamentales a cambio del voto, las penas aumentarán hasta en un tercio sobre lo previsto.

Se imponen también multas de mil a cinco mil días multa y de cinco a 15 años de prisión al que por sí o por un intermediario aporte, utilice o reciba aportaciones de dinero o en especie a favor de algún precandidato, candidato, partido político, coalición o agrupación política cuando exista una prohibición legal para ello, o se utilicen fondos o bienes con un origen ilícito, o que rebasen los permitidos por la ley.

Se agregan penas de 2 a 9 años de prisión al precandidato, candidato, funcionario partidista u organizadores de actos de campaña cuando aprovechen fondos, bienes o servicios en apoyo o perjuicio de otro contendiente.

A servidores públicos que cometan cualquier delito previsto, además de la inhabilitación para ocupar un cargo en el servicio público federal, local, municipal, estatal, delegacional o en el DF

6 GRANADOS, Omar, “¿En qué consiste la reforma político-electoral?”, en Animal Político, sitio especializado en información y análisis político mexicano, edición del 16 de mayo de 2014, México, 2017, consultada el 13 de enero de 2017, disponible en http://www.ine.mx/archivos2/CDD/Reforma_Electoral2014/descargas/articulos/Animal Politico_16may2014_OmarGranados.pdf 
y se les impondrá de dos a seis años y, en su caso, la destitución del cargo. ${ }^{7}$

La señalada norma punitiva, se integra por tres títulos en donde se disponen:

a) Las cuestiones básicas que se aplican a las leyes generales, como los objetivos y las definiciones generales.

b) La sinergia que se deberá de generar entre los diferentes niveles de gobierno, a efecto de atender la investigación, persecución y sanción de los delitos electorales, y de igual modo, los niveles de competencia entre las instituciones del orden federal y estatal.

c) Los tipos penales relativos al panorama electoral, y el procedimiento común para su aplicación.

\section{Los delitos electorales: conceptualización y marco normativo nacional}

Para comprender el abordaje doctrinal que hacemos en este subtítulo, debemos tener claro que:

- Un delito es un acto u omisión que sancionan las leyes penales.

- Los delitos electorales son un conjunto de previsiones jurídicas que buscan sancionar las conductas que atentan contra "la transparencia y objetividad del proceso electoral", la igualdad y la libre manifestación del voto. Con su persecución se pretende restaurar "la pureza de los resultados" electorales.

Para la Fiscalía Especializada para la Atención de Delitos Electorales (FEPADE), "los delitos electorales son aquellas acciones u omisiones que lesionan o ponen en peligro el adecuado desarrollo de la función electoral y atentan contra las características del voto, que debe ser uni-

7 Ibídem. 
versal, libre directo, personal, secreto e intransferible".

Asimismo, es toda acción u omisión típica, antijurídica culpable y punible, que sancionan las leyes penales, que lesionan o ponen en peligro el desarrollo del proceso electoral.

Por sus consecuencias, el delito electoral es el acto u omisión que afecta la limpieza, libertad y transparencia de un proceso electoral, y la prescripción legal considera una sanción para su autor, que va desde la imposición de una multa, de una pena privativa de libertad, o la inhabilitación del ejercicio de ciertos derechos. Son considerados delitos de lesa nación, ya que atentan contra la soberanía del pueblo. Los delitos electorales son conductas descritas y sancionadas por la Ley General en Materia de Delitos Electorales que lesionan o ponen en peligro el adecuado desarrollo de la función pública electoral federal, explica la FEPADE en su página oficial, y afirma que son responsables de delitos electorales quien o quienes atentan contra los principios de objetividad, transparencia, igualdad y libertad, que han de regir un sistema electoral democrático.

La sanción de este tipo de delitos va desde la imposición de una multa, pago de una cierta cantidad de dinero, pena privativa de libertad, o inhabilitación del ejercicio de ciertos derechos.

\section{1. ¿Quién puede ser sujeto activo en la comisión de esta conducta delictiva?}

Cualquier persona, funcionarios electorales, funcionarios o representantes de partido, ciudadanos, precandidatos, candidatos, servidores públicos, organizadores de campañas y ministros de culto religioso.

Desde la dogmática jurídico-penal, en el contexto del derecho electoral penal, se tiene esta referencia sobre el sujeto activo y pasivo del delito electoral

- Sujeto Activo. Pueden ser todas las personas físicas mexicanas o extranjeras que pretendan obstaculizar o entorpecer el desarrollo del

8 "Delitos electorales", catálogo publicado por la FEDADE, en su sitio electrónico disponible en $h t t p: / / w w w$.fepade.gob.mx/delitos.html, consultado el 14 de enero de 2017. 
proceso electoral o relacionadas con el proceso electoral.

- Sujeto Pasivo. Es todo aquel ciudadano mexicano que en goce de sus garantías constitucionales y que es privado injustificadamente, manipulado o coaccionado para poder emitir el sufragio a favor de un determinado candidato o partido político. ${ }^{9}$

Algunos ejemplos de este tipo de ilícitos son: Recoger credencial de elector; Alterar el Registro Federal de Electores; Desviar recursos públicos federales; Compra de votos; Votar sin credencial de elector; Votar con una credencial que no es suya; Votar más de una vez en una elección; Presionar en la casilla para que voten por algún partido o candidato; Hacer propaganda el día de la jornada electoral; Recoger la credencial de otro ciudadano sin razón aparente; Proporcionar información falsa al INE, por mínima que sea, cuando se tramita la credencial de elector; Interferir o obstaculizar el proceso electoral

Para la Fiscalía electoral mexicana, se describe la prohibición de las siguientes conductas en donde se relacionan no sólo ciudadanos, sino también funcionarios públicos, ministros de culto, representantes políticos y populares y fedatarios:

- Ninguna persona puede recoger en cualquier tiempo, sin causa prevista por la ley, una o más credenciales para votar de los ciudadanos.

- Nadie puede organizar una reunión o el transporte para llevarte a votar y te digan por quién votar.

- Los servidores públicos no pueden condicionar la prestación de un servicio público, el cumplimiento de programas gubernamentales, el otorgamiento de concesiones, permisos, licencias, autorizaciones, franquicias, exenciones o la realización de obras públicas, en el ámbito de su competencia, a la emisión del sufragio en favor de un precandidato, candidato, partido político o coalición; a la abstención del ejercicio del derecho de voto o al compromiso de no votar a favor de un precandidato, candidato, partido o coalición.

9 "Delitos electorales", en Concepto jurídico, sitio digital especializado en el tratamiento de temas jurídicos, consultado el 12 de enero de 2017, y disponible en el sitio electrónico http://definicionlegal.blogspot.mx/2012/10/delitos-electorales.html 
- Queda prohibido que los servidores públicos coaccionen, induzcan o amenacen a sus subordinados para que voten o se abstengan de votar por una opción dentro de la consulta popular.

- Los funcionarios electorales tienen prohibido alterar los resultados electorales, sustraer o destruir boletas, documentos o materiales electorales.

- Es delito que los funcionarios partidistas impidan la instalación, apertura o clausura de una casilla, así como el escrutinio y cómputo, el traslado y entrega de los paquetes y documentación electoral, o el adecuado ejercicio de las tareas de los funcionarios electorales.

- Queda prohibido que los ministros de culto religioso presionen o induzcan el sentido del voto o a votar o abstenerse de votar por un candidato, partido político o coalición, en ejercicio del culto religioso o en desarrollo de actos propios de su ministerio.

- Se considera una práctica delictiva que los diputados y senadores habiendo sido electos a un cargo de elección popular no se presenten, sin causa justificada a juicio de la Cámara, Asamblea Legislativa o Cabildo respectivo, a desempeñar el cargo, dentro del plazo previsto para tal efecto en el ordenamiento jurídico respectivo.

- Los fedatarios públicos pueden cometer un delito electoral cuando estando obligados se nieguen injustificadamente a dar fe de hechos o certificar documentos concernientes a la elección.

- Queda prohibido que los exmagistrados electorales, consejeros electorales y el secretario ejecutivo del Instituto Nacional Electoral desempeñen o sean designados en cargos públicos por los Poderes Ejecutivo o Legislativo cuya elección hayan calificado o participado, asuman cargos de dirigencia partidista o sean postulados a cargos de elección popular, dentro de los dos años siguientes a la conclusión de su encargo. ${ }^{10}$

\subsection{Objeto material y jurídico}

En esta parte, observamos que el objeto material son los electores, a los

10 "Delitos electorales" catálogo..., op. cit. 
que se obstaculiza o interfiere el derecho a votar libremente; también lo serán los paquetes y documentos electorales respecto de los cuales se impide o interfiere su traslado o entrega, así como los funcionarios electorales quienes no pueden realizar sus actividades por las mencionadas conductas.

El objeto jurídico es el conjunto de principios que rigen la función electoral, y "en donde se pretende impedir la lesión o puesta en peligro de éstos y de su eficacia, evitando con ello el descrédito de las instituciones encargadas de la renovación del poder público". ${ }^{11}$

\subsection{Marco normativo nacional}

El soporte jurídico que enmarca el combate a los actos delincuenciales frente a los procesos electorales, se integra en los siguientes documentos:

- Constitución Política de los Estados Unidos Mexicanos, artículo 73, fracción XXI, inciso a);

- Ley General en materia de Delitos Electorales, en sus tres títulos; $\mathrm{y}$

- Código Penal Federal, en los artículos 401 al 408 y del 411 al 413, en los que se establecen más de 150 hipótesis delictivas o tipos penales.

\subsection{Bien jurídico tutelado}

El fin que persigue el derecho penal es el de proteger aquellos intereses de la sociedad, de las personas, y de los grupos, que bajo ciertas directrices culturales se consideran superiores y fundamentales para la subsistencia del Estado, así como para el bienestar de los individuos y sus relaciones entre ellos mismos y con los órganos de gobierno; en vista de ello, con el objeto de proteger eficazmente esos intereses, se definen como delitos, y se sancionan como tales, aquellas conductas que a juicio del legislador los vulneran con gravedad.

Son aquellos bienes vitales imprescindibles para la convivencia humana en sociedad que son, por tanto, merecedores de protección a través

11 “Delitos electorales”, en Concepto jurídico..., op. cit. 
del poder coactivo del Estado representado por la pena pública.

Para que en una sociedad prevalezca el Estado de Derecho y tenga éxito en sus relaciones sociales, se deben de proteger determinados intereses, los cuales deben de ser relevantes y protegidos por el derecho; como lo son la vida, el patrimonio, la libertad, entre otros; éstos para ser cobijados dentro de la Constitución deben de someterse a un proceso legislativo determinado; por lo que existen bienes jurídicos de protección penal, de tutela civil, laboral, administrativa, etc. Los bienes jurídicos que merecen tutela penal, son los bienes jurídicos penales.

Protegen los intereses o valores más altos de la sociedad. Y alcanzan el carácter de jurídicos cuando son reconocidos por el Estado al plasmarlos en la ley.

Como ejemplo de estos valores supremos tenemos: la vida, la libertad, la familia, la salud, la integridad física, el libre desarrollo de las personas, el patrimonio, etc.

La ausencia de un bien jurídico que preservar despoja a la norma penal de todo contenido material, como también de toda legitimidad.

Como referencia de la construcción doctrinal sobre los bienes jurídicos, tenemos la opinión de los siguientes autores clásicos:

Franz von Liszt dice que los bienes jurídicos "son intereses vitales, intereses del individuo o de la comunidad; intereses, por tanto, preexistentes a la valoración del legislador y, como tales, idóneos para garantizar la correspondencia entre realidad social y régimen normativo"

Karl Binding afirma que "son una creación exclusiva del legislador, quien actúa sin otra limitación que su propia consideración y la que impone la lógica”. El bien jurídico es el derecho intrínseco que la norma protege, no es otra cosa que la pretensión del legislador de darle protección a ciertos valores del ser humano, y que estos se conviertan en intereses no sólo personales sino sociales y del Estado.

El concepto de bien jurídico ha cumplido hasta hoy importantes funciones en la dogmática penal; lo ha hecho como criterio para la clasificación de los delitos, y como elemento de base y límite al orden penal.

Feuerbach nos hablaba ya de la lesión a un derecho subjetivo como elemento legitimante de la facultad punitiva del Estado. 
Los bienes jurídicos son aquellos vitales e imprescindibles para la convivencia bumana en sociedad que son, por tanto, merecedores de protección a través del poder coactivo del Estado representado por la pena pública.

Raúl Eugenio Raúl Zaffaroni expresa que no es posible concebir una conducta típica sin la justificación de la necesidad de tutelar un bien jurídico, de ahí que el bien jurídico desempeña un papel central en la teoría del tipo, dando un verdadero sentido teológico a la ley penal.

Protegen los intereses o valores más altos de la sociedad. Y alcanzan el carácter de jurídicos cuando son reconocidos por el Estado al plasmarlos en la ley.

Como ejemplo de estos valores supremos tenemos: la vida, la integridad física, la libertad, la salud, el patrimonio y el libre desarrollo de las personas, etc.

La legislación penal no crea bienes jurídicos, sino que éstos son creados por la Constitución, el derecho internacional y el resto de la legislación. El derecho penal recibe el bien jurídico ya tutelado y la norma que se deduce del tipo no hace más que anunciar un castigo para ciertas formas particulares y aisladas de lesión al mismo.

El bien jurídico tutelado en materia electoral, responde a la variedad de delitos que existen en la norma penal, y por tanto pluri-ofensivos; dentro de los bienes jurídicos tutelados por estas descripciones típicas normativas encontramos a los siguientes:

$>\mathrm{El}$ derecho al voto y sus características de universal, libre, secreto, directo, personal e intransferible;

$>$ La libre expresión de la voluntad política en materia política;

$>\mathrm{La}$ imparcialidad, y el debido funcionamiento y buen desempeño de los órganos electorales;

$>$ La pulcritud, y la libre organización y realización de los procesos electorales;

La preservación de las condiciones legales de toda contienda electoral;

$>$ La inbibición de la utilización de fondos, bienes o servicios estatales con el propósito de favorecer a un partido político o determinado candidato;

$>$ La preservación de los principios de autenticidad, certeza y con- 
fiabilidad en los documentos públicos electorales, como el padrón electoral, las listas nominales de electores y la credencial para votar;

$>$ El mantenimiento de las condiciones de equidad para que los participantes compitan en igualdad;

$>$ La credibilidad de los comicios; y

La certeza en los resultados.

El bien jurídico protegido de los delitos electorales es la libre organización y realización de los procesos electorales para elegir a los titulares de un cargo público; el bien jurídico tutelado es el sufragio y sus características de universal, libre, secreto, directo, personal e intransferible, así como velar por el debido funcionamiento de los órganos electorales.

El voto es la expresión de la voluntad ciudadana mediante la cual ejerce su derecho a elegir gobernantes y representantes de forma democrática a travé de elecciones libres, auténticas y periódicas. El voto es universal, libre, secreto, directo, personal e intransferible, y deberá ser respetado por autoridades, partidos políticos y candidatos.

$\mathrm{El}$ ejercicio del sufragio es la piedra angular que sostiene las democracia contemporáneas, "sin él, surge la imposición y la dictadura". El sufragio es una capacidad espacial que orden jurídico reconoce a determinadas personas para participar en la integración de la integración de los órganos del poder público. ${ }^{12}$

En esta parte del presente documento, es necesario acotar que los principios rectores del derecho electoral son la constitucionalidad, legalidad, certeza, objetividad, imparcialidad, independencia, autonomía, probidad, eficacia, profesionalismo, especialidad, capacidad, competencia, antecedentes profesionales, economía eficiencia, de manera completa y gratuita; a través de dichos principios se tratan de proteger los siguientes valores democráticos políticos electorales, mismos que corresponden a la anterior legislación:

12 IZAGUIRRE, Edy, Medios de impugnación en materia electoral, Editorial Novum, México, 2012, p. 16. 
- La soberanía nacional (art. 139 relacionado al 115 Constitucionales) entendiendo a la democracia como una expresión de la soberanía popular.

- La forma de gobierno (art. 40 relacionado con los 41, 49, 116 y 122 constitucionales).

- La libre participación política y el sufragio universal, libre, secreto, directo, personal, e intransferible (art. 35 en sus tres primeras fracciones, en relación al 41 constitucional, en relación al artículo 4 del COFIPE).

- El pluralismo político, condiciones de equidad para la competencia electoral y un sistema electoral, representativo (41 constitucional en relación al libro dos COFIPE)

- Seguridad jurídica (13 al 23 en relación a los 94 al 107 todos constitucionales). ${ }^{13}$

El principio de "lesividad" y la teoría de bienes jurídicos ha sido un tema que siempre ha ocupado y preocupado al ilustre profesor chileno Juan Bustos Ramírez. En el mundo hispanoparlante es por demás conocida su concepción que trata de sistematizar mejor y materializar este principio a través de su distinción entre "bienes individuales" y "bienes colectivos" y su integración en la construcción de la teoría del delito.

Los bienes jurídicos políticos tutelados en los delitos electorales, como puede colegirse, la sanción de las conductas descritas en los artículos 403, 404, y 407 del Código Penal Federal tienen la finalidad de que en los procesos electorales, los ciudadanos ajusten su actos a la reglas establecidas en el código federal de instituciones y procedimientos electorales, respecto de la forma de emitir el voto, el día de la elecciones “jornada electoral, protegiendo con ello el respeto a la ley, la libertad política del

13 OROZCO, Henríquez Jesús, "Consideraciones sobre los principios y valores tutelados por el derecho electoral federal mexicano", en revista Justicia Electoral, No. 9, Tribunal Electoral del Poder Judicial de la Federación, México, 1997, p. 85 a 107, citado por COVARRUBIAS DUEÑAS, José de Jesús, Derecho Constitucional electoral, $4^{\mathrm{a}}$ ed. Ed. Porrúa, México, 2005, p. 125. 
secreto del voto. ${ }^{14}$ En sentido general, aquel bien que el derecho ampara o protege. Su carácter jurídico deviene de la creación de una norma jurídica que prescribe una sanción para toda conducta que pueda lesionar dicho bien. Sin la existencia de esa norma, que tiene que estar vigente y ser eficaz, el bien pierde su carácter jurídico. ${ }^{15}$

\section{Democracia: acepciones, connotaciones y conceptos}

Cuando nos encontramos ante la necesidad de caracterizar al vocablo democracia, nos encontramos que en torno al mismo existe una muy amplia gama de acepciones, las que generan una falta de claridad y precisión, por lo que su conceptualización se erige en una tarea con cierto grado de complejidad que requiere de una exhaustiva revisión a la literatura política, la que arroja una serie de significados, connotaciones y dimensiones, a los que habrá de sumarle que, la democracia implica una categoría que en el devenir de los tiempos, registra una evolución y significativa trasformación.

Las acepciones más recurrentes son las que siguen:

- Poder del pueblo;

- Participación ciudadana;

- Doctrina política;

- Forma de organización y convivencia de la sociedad;

- Forma de organización del Estado;

- Régimen o sistema de gobierno;

- Valor o principio de la modernidad; y

-Derecho fundamental.

14 IBARRA FLORES, Román, La defensa legal del voto en las elecciones federales", Editorial. OGS, México, 2000, p. 170.

15 "Bien Jurídico", en Enciclopedia Jurídica, página especializada en etimología jurídica, consultada el 10 de diciembre de 2016, disponible en el sitio electrónico http://www.enciclopedia-juridica.biz14.com/d/bien-jur\%C3\%ADdico/bienjur\%C3\%ADdico.htm 
Democracia es un término antiquísimo, podríamos decir milenario, que surge en Grecia en el año 508 a.C., y desde ese entonces se sabe que el término democracia deviene del vocablo griego demos, que significa pueblo, y kratos, que significa gobierno o poder. De lo anterior se desprende que democracia es el gobierno del pueblo. Este aforismo es, digamos, considerado el concepto de trajín, que en la actualidad se encuentra rebasado, y resulta insuficiente para explicar a la democracia de nuestros tiempos.

El significado ha evolucionado con el tiempo, y es importante señalar que en la actualidad se conciben nuevas democracias que van más allá de lo propiamente electoral.

En términos generales la democracia alude a un sistema de gobierno en el cual la soberanía o la autoridad del poder se encuentran depositadas en el pueblo; es por ello que, cuando hablamos de democracia, pensamos en el régimen político o en una forma de gobierno, que incluye normas, instituciones, prácticas y actos vinculados al acceso y ejercicio del poder.

La democracia como forma de gobierno se traduce pues, en la participación de la ciudadanía en la acción gubernamental, a través de la emisión del sufragio, es decir supone la existencia de elecciones libres, periódicas y competitivas; y el control, limitación y regulación que ejerce sobre la actuación del Estado.

Para Norberto Bobbio, la democracia debe concebirse como "un método o un conjunto de reglas de procedimiento para la constitución del gobierno y para la formación de las decisiones políticas, en el que está prevista la más amplia participación posible de los interesados".

En la etapa contemporánea existe una connotación más amplia de la democracia, que la concibe no solo como una estructura jurídica y un régimen político, sino además como un sistema de vida fundado en el constante mejoramiento económico, social y cultural del pueblo, tal como lo establece la Constitución Política de los Estados Unidos Mexicanos en su artículo 3o., fracción II; en tenor de ello, la democracia es también entendida como una forma de convivencia social, y un estilo de vida fincado en el respeto a la dignidad humana, la libertad y el respeto a los derechos ciudadanos de todos y cada uno de los miembros de determinada sociedad. 
Sin embargo, "representa una idea antiquísima la historia del pensamiento político: es la idea del gobierno de los hombres, contrapuesta a la del gobierno de las leyes, criticada ya por platón y Aristóteles. Una ilusión que siempre vuelve a proponerse en los momentos de crisis de la democracia". ${ }^{16}$

La palabra democracia es un término que suele confundir con formas no democráticas cuando se usa para designar a gobiernos totalitarios, dictatoriales o autoritarios, los cuales son arbitrarios perversos y represivos. El significado de la palabra puede ser desvirtuado al entender a estos como gobiernos democráticos pese a que no son electos popularmente y deciden por todos sin tomar en cuenta las opiniones o preferencia de la ciudadanía, y a que esta carece del reconocimiento de sus derechos políticos para participaren la conformación del gobierno

El derecho electoral trata de salvaguardar el contenido y continente de la democracia, a partir de un conjunto de normas, principios y valores de derecho positivo consuetudinarias que tienen como propósito la regulación de las formas, procesos y procedimientos a través de los cuales se trasmite el poder en México, y a su vez establece, las garantías político electorales, tanto para los administrados como para los que gobiernan, protegen y controlan la constitucionalidad y la legalidad de los actos y resoluciones electorales, tanto en los ente federados como de la Federación. ${ }^{17}$

En el progreso del constitucionalismo, se han confrontado dos concepciones de la democracia: la primera concepción denominada democracia constitucional, y democracia liberal. ${ }^{18}$

Según la imagen simplificada propuesta por la primera concepción, nos pretende hacer entender la igualdad, y puntualiza que la democracia

16 FERRAJOLI, Luigi, Democracia y Garantismo, Editorial Trota, Madrid, 2008, p. 26.

17 COVARRUBIAS DUEÑAS, José de Jesús, Naturaleza jurídica del derecho electorera, Tesina presentada ante el Tribunal Electoral del Poder Judicial de la Federación en Guadalajara Jalisco, México enero 1999, citado por COVARRUBIAS DUEÑAS, José de Jesús, Derecho Constitucional electoral..., op. cit., p. 5.

18 FERRAJOLI, Luigi, Democracia y Garantismo..., op. cit., p. 23. 
consistiría esencialmente en la omnipresencia de la mayoría, o bien de la soberanía popular. ${ }^{19}$

En este tenor se sigue una serie de corolarios que la caracterizan, como la descalificación de reglas y de los límites del poder ejecutivo que es expresión de la mayoría, que traen como consecuencia la división de poderes, un sistema de contrapesos. ${ }^{20}$

Lo anterior de resume en la idea de que el consenso de la mayoría legitima cualquier abuso y que es la sustancia de aquello que lo constituye, la expresión más apropiada para contextualizar este tipo de democracia es el presidencialismo, es decir, la delegación a un jefe asumido como expresión directa de la soberanía popular; lo que Ferrajoli llama ideología de la mayoría.

Así pues, con el objeto de que una decisión tomada por individuos (uno, pocos, muchos, todos) pueda ser aceptada como una decisión colectiva, es necesario que sea tomada con base en reglas (no importa si son escritas o consuetudinarias) que establecen quiénes son los individuos autorizados a tomar las decisiones obligatorias para todos los miembros del grupo, y con qué procedimientos. Ahora bien, por lo que respecta a los sujetos llamados a tomar (o a colaborar en la toma de) decisiones colectivas, un régimen democrático se caracteriza por la atribución de este poder (que en cuanto autorizado por la ley fundamental se vuelve un derecho) a un número muy elevado de miembros del grupo. ${ }^{21}$

Los ciudadanos de la democracia moderna y plural disfrutan de los mismos derechos y privilegios fundamentales a pesar de sus potenciales y numerosas diferencias en cuanto a cultura, etnia, religión, riqueza o capacidad. Todos ellos quedan incluidos dentro del conjunto de beneficiarios del orden constitucional. Un rasgo central de los principios y normas políticas de la democracia liberal es que son universales. Consideran por

19 Ibídem, p. 25.

20 Ibídem, p. 23.

21 BOBBIO, Norberto, El futuro de la democracia, Fondo de Cultura Económica, Séptima reimpresión, México, 2012, pp. 24-25. 
igual los intereses de todos los ciudadanos y se aplican a todos los miembros de la sociedad de forma indiscriminada. ${ }^{22}$

Nos dice Sartori que si vamos a definir la democracia de manera "irreal", no encontraremos nunca "realidades democráticas". Y a veces, cuando declaremos "esto no es democracia" o "esto no lo es", quedará claro que el juicio depende de la definición o de nuestra idea sobre qué es la democracia, qué puede ser o qué debe ser. ${ }^{23}$

\subsection{La democracia como un bien jurídico tutelado de los delitos electorales}

Los argumentos en los que descansa la afirmación de que la democracia se erige en un bien jurídico tutelado de los delitos electorales, son los siguientes:

El legislador al estipular que, con los delitos electorales se pretenden tutelar:

- Las elecciones libres, auténticas y periódicas, y su realización mediante la emisión del sufragio universal, libre, secreto y directo;

- Las condiciones de equidad para que los participantes de la contienda electoral compitan como iguales;

- La preservación de los principios rectores del proceso electoral: certeza, legalidad, independencia, imparcialidad y objetividad, como una tarea de Estado.

En tal sentido, los delitos electorales protegen los principios que han de regir un sistema electoral en el marco de un Estado democrático. La democracia no son las paradas sino el viaje mismo:

- Al hablar de delitos en materia electoral o contra la democracia electoral, se deduce que lo que se pretende tutelar es precisamente al sistema democrático;

22 BAURMAN MICHAEL, Martí et al, Los desafíos de la democracia, $1^{a}$ ed., Editorial Fontamara, México, 2013, p. 13.

23 SARTORI, Giovanni, ¿Qué es la democracia?, editorial Taurus, México, 2003, p. 21. 
- El carácter esencial que tiene el libre ejercicio del derecho de sufragio brinda el sustento valorativo propio de un sistema democrático, justificando la intervención del derecho penal para incriminar aquellos comportamientos idóneos para lesionar o poner en peligro al referido sistema;

- El legislador con los delitos electorales en su conjunto procuró proteger el correcto funcionamiento de las instituciones democráticas y republicanas;

- Si para la teoría penal dominante el bien jurídico se traduce en un derecho, y la democracia es también considerada contemporáneamente un derecho, ésta última, sin duda, puede constituirse en un bien jurídico tutelado de las infracciones penales en comento;

- Los bienes jurídicos se integran por intereses o valores que pueden ser: individuales, sociales, del Estado y de personas morales, sin duda la democracia en la actualidad es también considerada un valor;

- El valor de libertad y el principio de celebrar elecciones periódicas y genuinas mediante el sufragio universal son elementos esenciales de la democracia;

- Los valores de la democracia, como la justicia, la igualdad, la legalidad, la libertad, la participación, el pluralismo, el respeto y la tolerancia, son también factores que eventualmente pueden ser vulnerados con la comisión de los delitos electorales;

- En la exposición de motivos de la Ley en materia de delitos electorales se deja ver que si bien una democracia no debe fundarse en el derecho penal y que ésta debe ser la ultima ratio del Estado, la realidad es que tampoco pueden dejarse en el tintero sanciones ejemplares hacia aquellas personas que atentan en contra de cualquier valor fundamental sobre el que se basa una sociedad. Máxime si trata de salvaguardar los valores democráticos sobre los que se funda el sistema electoral mexicano.

Los tipos descritos en la ley, tienden a castigar a quien haya puesto en peligro la transparencia del proceso electoral, y así evitar la comisión de actos que pongan en duda los resultados del propio proceso, con lo que se permitirá el imperio de la democracia por medio del sufragio. 


\section{Reflexiones finales}

En el contexto actual, los delitos electorales en México debieran tener una importancia de primer orden. Cuando las elecciones se desarrollan cumpliendo las reglas de la competencia política, tanto del ámbito normativo como en el ético, simplemente los delitos electorales pueden ser innecesarios.

Los delitos electorales son figuras típicas que se ejecutan a través de la comisión de diversas conductas, que se cometen mediantes múltiples modalidades, por ende son categorías pluri-ofensivas, que afectan diversos bienes jurídicos.

La democracia se erige en uno de los bienes jurídicos de mayor trascendencia y jerarquía que tutelan los delitos de carácter electoral.

Actualmente los tres poderes en México, que son instrumento del ejercicio de la fuerza de unos cuantos sobre los derechos de la persona, y de las mayorías, han pervertido el modelo original, ya que tanto en los poderes como en lo partidos políticos, se ha convertido en un todo sistémico, y unitario que sirve a sí mismo y que utiliza a la comunidad y a la sociedad como pretexto para ejercer una nueva forma de oligarquía absoluta y abusiva con altos riesgos para preservar el pacto social.

Y como refieren Gertz y Maldonado, este es el momento idóneo para generar un nuevo paradigma, creando un cuarto poder, que se conforme por los ciudadanos y la comunidad, que cumpla con las funciones de vigilar, auditar, exigir cuentas y promover sanciones a los otros tres poderes, representando de igual forma a la comunidad de una manera integral en sus derechos humanos, parta de esa manera volver a contener el repetitivo del abuso del poder y de la autoridad que ha desvirtuado los principios democráticos. ${ }^{24}$

Porque, de lo contario, si no corregimos estas disfuncionalidades institucionales, la transición a la democracia sobre la que pretendemos soportar el progreso de nuestras sociedades en el Estado mexicano, corre un notable riesgo de quedarse sin su principal sujeto, esto es, el ciudadano, y la legitimidad que brinda su presencia en las políticas públicas.

24 GERTZ, Alejandro y MALDONADO, Luis, Democracia real y poder ciudadano, primera edición, Editorial Miguel Ángel Porrúa, México, 2009, p. 6. 


\section{Fuentes de información}

BAURMAN MICHAEL, Martí et al, Los desafíos de la democracia, $1^{\mathrm{a}}$ ed., Editorial Fontamara, México, 2013.

BOBBIO, Norberto, El futuro de la democracia, Fondo de Cultura Económica, Séptima reimpresión, México, 2012.

COVARRUBIAS DUEÑAS, José de Jesús, Naturaleza jurídica del derecho electore$r a$, Tesina presentada ante el Tribunal Electoral del Poder Judicial de la Federación en Guadalajara Jalisco, México enero 1999.

FERRAJOLI, Luigi, Democracia y Garantismo, Editorial Trota, Madrid, 2008.

GERTZ, Alejandro y MALDONADO, Luis, Democracia real y poder ciudadano, primera edición, Editorial Miguel Ángel Porrúa, México, 2009.

GRANADOS, Omar, “¿En qué consiste la reforma político-electoral?”, en Animal Político, sitio especializado en información y análisis político mexicano, edición del 16 de mayo de 2014, México, 2017, consultada el 13 de enero de 2017, disponible en el sitio digital http://www.ine.mx/archivos2/CDD/Reforma_Electoral2014/descargas/articulos/A nimalPolitico_16may2014_OmarGranados.pdf

IBARRA FLORES, Román, La defensa legal del voto en las elecciones federales”, Editorial OGS, México, 2000.

IZAGUIRRE, Edy, Medios de impugnación en materia electoral, Editorial Novum, México, 2012.

Ley General de Instituciones y Procedimientos Electorales, publicada en el Diario Oficial de la Federación, el 23 de mayo de 2014, Congreso de la Unión, Cámara de Diputados, México, 2014.

Ley General de Partidos Políticos, publicada en el Diario Oficial de la Federación, el 23 de mayo de 2014, Congreso de la Unión, Cámara de Diputados, México, 2014.

Ley General en Materia de Delitos Electorales, publicada en el Diario Oficial de la Federación, el 23 de mayo de 2014, Congreso de la Unión, Cámara de Diputados, México, 2014.

OROZCO, Henríquez Jesús, "Consideraciones sobre los principios y valores tutelados por el derecho electoral federal mexicano", revista Justicia Electoral No. 9, Tribunal Electoral del Poder Judicial de la Federación, México, 1997. 
Reforma politico electoral, documento publicado por el gobierno federal acerca de esta reforma sustantiva al sistema electoral mexicano, Gobierno de la República, México, 2014.

SARTORI, Giovanni, ¿Qué es la democracia?, editorial Taurus, México, 2003.

"Bien Jurídico", en Enciclopedia Jurídica, página especializada en etimología jurídica, consultada el 10 de diciembre de 2016, disponible en el sitio electrónico http:// www.enciclopedia-juridica.biz14.com/d/bien-jur\%C3\%ADdico/bienjur $\%$ C3\% ADdico.btm

"Delitos electorales", catálogo publicado por la FEDADE, en su sitio electrónico disponible en http://www.fepade.gob. $m x$ /delitos.html, consultado el 14 de enero de 2017.

"Delitos electorales", en Concepto jurídico, sitio digital especializado en el tratamiento de temas jurídicos, consultado el 12 de enero de 2017, y disponible en el sitio electrónico http://definicionlegal.blogspot.mx/2012/10/delitoselectorales.html 